\title{
The role of deubiquitinating enzymes in gastric cancer (Review)
}

\author{
JIANGANG SUN $^{1}$, XIAOJING SHI $^{2}$, M.A.A. MAMUN ${ }^{2}$ and YONGSHUN GAO ${ }^{1}$ \\ ${ }^{1}$ Department of Gastrointestinal Surgery, The First Affiliated Hospital of Zhengzhou University, Zhengzhou, Henan 450052; \\ ${ }^{2}$ Zhengzhou University School of Pharmaceutical Science, Zhengzhou, Henan 450001, P.R. China
}

Received February 27, 2019; Accepted October 22, 2019

DOI: $10.3892 / 01.2019 .11062$

\begin{abstract}
The epigenetic regulation of gene expression (via DNA methylation, histone modification and microRNA interference) contributes to a variety of diseases, particularly cancer. Protein deubiquitination serves a key role in the mechanism underlying histone modification, and consequently influences tumor development and progression. Improved characterization of the role of ubiquitinating enzymes has led to the identification of numerous deubiquitinating enzymes (DUBs) with various functions. Gastric cancer (GC) is a highly prevalent cancer type that exhibits a high mortality rate. Latest analysis about cancer patient revealed that GC is sixth deadliest cancer type, which frequently occur in male (7.2\%) than female (4.1\%). Complex associations between DUBs and GC progression have been revealed in multiple studies; however, the molecular mechanism underpinning the metastasis and recurrence of GC is yet to be elucidated. Generally, DUBs were upregulated in gastric cancer. The relation of DUBs and tumor size, classification and staging was observed in GC. Besides, 5-yar survival rate of patients with GC is effeccted by expression level of DUBs. Among the highly expressed DUBs, specifically six DUBs namely UCHs, USPs, OTUs, MJDs, JAMMs and MCPIPs effect on this survival rate. Consequently, the association between GC and DUBs has received increasing attention in recent years. Therefore, in the present review, literature investigating the association between DUBs and GC pathophysiology was analyzed and critically appraised.
\end{abstract}

\section{Contents}

1. Introduction

2. UCHs and GC

3. USPs and GC

Correspondence to: Professor Yongshun Gao, Department of Gastrointestinal Surgery, The First Affiliated Hospital of Zhengzhou University, 1 East Road, Erqi, Jianshe, Zhengzhou, Henan 450052, P.R. China

E-mail: gaoys@zzu.edu.cn

Key words: deubiquitinating enzymes, gastric cancer, survival
4. OTUs and GC
5. MJDs and GC
6. JAMMs and GC
7. MCPIPs and GC
8. Conclusion and future perspectives

\section{Introduction}

Epigenetic mechanisms are implicated in tumorigenesis and cancer progression, and are defined as heritable changes that do not affect the DNA sequence. Examples include DNA methylation, histone modification and microRNA (miR) interference (1). Histone modification serves an important role in transcriptional regulation, DNA repair and replication, and chromosomal condensation. Several studies have indicated that histone modifications typically occur at the $\mathrm{N}$-terminus, primarily in the form of acetylation, methylation, phosphorylation or ubiquitination $(2,3)$.

Ubiquitination describes a post-translational modification of proteins under the conditions of normal homeostasis or disease, which involves the addition of the evolutionarily conserved small protein ubiquitin (4) or UBLs (ubiquitin-like proteins) (5) that tag the protein for proteasomal degradation or non-degradative processes (6). Ubiquitin is a 76-amino acid polypeptide that can covalently conjugate with protein substrates via a mechanism involving three enzymes: Ubiquitin-activating (E1), ubiquitin-conjugating (E2) and ubiquitin ligase (E3). The ubiquitination of a specific protein substrate requires the selective recruitment of E1, E2 and E3 (7-9). In eukaryotic cells, the structure of ubiquitin is highly conserved and the protein responds to certain chemical signals (such as phosphorylation, oxidation, misfolding and damage to the ubiquitinated protein) to induce the ubiquitin-proteasome degradation pathway (10). Notably, the activity of deubiquitinating enzymes (DUBs) directly influences the turnover rate, activity, regeneration and localization of various proteins in cells. In addition, DUBs serve an important role in homeostasis (11), the stabilization and degradation of proteins, and signal transduction pathways (11). Changes in protein structure, abnormal spatial and temporal expression, and uncontrolled activity can result in the development of certain conditions, including arthritis, neurodegenerative and cardiovascular diseases, and tumors. In humans, DUBs can serve a role in the genesis of tumors as either oncogenes or tumor suppressor genes. 
The DUB protein family reportedly comprises 103 members, the majority of which are cysteine proteases. As a result of similarities in their amino acid sequences and molecular structures, these proteins can be divided into the following six families: Ubiquitin C-terminal hydrolases (UCHs) (12), ubiquitin-specific proteases (USPs), ovarian tumor-related proteases (OTUs), Machado-Joseph disease protein domain proteases (MJDs), Jab1/MPN domain-associated metalloisopeptidase (JAMM) domain proteins and monocyte chemotactic protein-induced proteins (MCPIPs) (13). To further summarize and stratify the aforementioned proteins, subfamilies are also detailed in Fig. 1. USP16 (14), USP6NL (15), ubiquitin thioesterase otulin (OTULIN) (16) and family with sequence similarity 105 member A (FAM105) (17) were also recently discovered. The majority of these DUBs are associated with tumor progression and several studies have revealed the association between DUBs and gastric cancer (GC) $(18,19)$. Of note, $\mathrm{GC}$ is the second leading cause of cancer-associated mortality and the fourth most common cancer type worldwide $(20,21)$.

The lack of a comprehensive understanding of the molecular mechanism underpinning GC metastasis and recurrence suggests that further investigation is required. Thus, DUBs and their potential association with the progression of $\mathrm{GC}$ were the primary focus of the present review. Within the present study, subsequent data analyses were performed using the Gene Expression Profiling Interactive Analysis (GEPIA) website (http://gepia.cancer-pku.cn), which primary collates data from The Cancer Genome Atlas and the Genotype-Tissue Expression project databases. The name of a each target gene was input into the GEPIA website and the corresponding data was extracted (22).

\section{UCHs and GC}

The enzymes of the UCH protein family contain a conserved catalytic domain known as the UCH domain, which comprises $\sim 230$ amino acids (23). This protein family includes four members, including UCHL1/protein gene product 9.5, UCHL3, UCHL5/UCH37 and BRCA1 associated protein-1 (BAP1) (24-27). The activities of these proteins have been associated with the occurrence and development of cancer, and several studies have identified that UCHL1, UCHL5 and BAP1 are specifically involved in the formation of GC (24-26).

Using data extracted from GEPIA, the gene expression profiles of UCHs between GC samples and the paired normal tissues are presented in Fig. 2. The gene expression levels of UCHL 3 and UCHL5 in tumor tissues were upregulated $>2$-fold compared with normal tissues. To the best of our knowledge, no studies have reported the link between UCHL3 and GC; however, UCHL5 has been identified as a potential biomarker of GC with novel prognostic value. For elderly patients with dysregulated protein homeostasis, high levels of UCHL5 inhibited proteasome activity, and were determined to promote the apoptosis of cancer cells (28). Regarding UCHL1, research has shown that it could be a candidate biomarker and therapeutic target for GC metastasis, as UCHL1 promoted this process via the Akt and Erk1/2 pathways (29). BAP1 expression is downregulated in gastric carcinoma and its decreased expression was associated with a malignant phenotype (histological grade) and a more advanced TNM stage (30). Furthermore, low BAP1 expression was revealed to be associated with poor prognosis in patients with gastric adenocarcinoma and GC (30).

Associations between UCHs and certain clinicopathological features, and the 5-years survival rates of patients with GC are presented in Table I. High expression levels of UCHs in patients with GC were predominantly associated with tumor size and TNM stage, but not sex or age. Analysis of these expression levels indicated that the higher the degree of positive BAP1 and UCHL5 expression in GC, the higher the 5-year survival rate of patients. Conversely, increased expression of UCHL1 was revealed to reduce the survival rate of patients.

\section{USPs and GC}

USPs are the most diverse family of DUBs and the USP subclass represents the majority of DUBs encoded by the human genome. Consequently, numerous studies have investigated their function, substrates and mechanisms of action in various diseases. The discovery of gene mutations and the upregulation of USPs in various types of cancer, and their potential for targeted small molecule-mediated inhibition, indicates USPs as a promising therapeutic target. There is also increasing interest in the development of USP-specific inhibitors as antiviral and anticancer agents (31). In the present study, the USP family was stratified into 10 subgroups comprising USPs 1-10. The gene expression profile of USPs was compared between GC and paired normal tissues (Fig. 3).

USP1s and GC. The USP1 subfamily includes 11 members: USP1 (32), USP10-13 (33-36), USP14-16 (37-39), USP17L2 (40), USP18 (41) and USP19 (42). Of the USP1 subfamily members investigated, the expression levels in CG tissues was higher compared with those in the adjacent normal tissues (Fig. 3). The expression levels of USP13 and USP18 were $<10$ Transcripts Per Million (TPM), which were relatively low compared with the other USP1s investigated (which were expressed at levels $>10$ TPM). USP17L2 expression was not detected. The highest levels of expression were noted for USP10, followed by USP14 and USP11, which exhibited expression levels $>20$ TPM.

The expression of the majority of USP1s has been associated with tumor growth, though studies into GC have predominantly investigated USP10, USP14 and USP15 (43). USP10 and USP14 are independent predictors of prognosis for patients with GC, and the increased expression of USP10 in GC has been associated with the 5-year survival rate of patients. A previous study demonstrated that the downregulation of USP10, as well as the absence of USP14 expression in GC cells had significant effects on gastric wall invasion and lymph node metastasis, increased malignant biological behavior and reduced survival rate, as determined from a large number of clinical samples $(44,45)$. Conversely, vimentin expression was upregulated in human GC tissues and cell lines as a result of deubiquitination, following interactions with USP14 and miR-320a, which may contribute to the aggressiveness of GC cells (46). It was also reported that the direct targeting of USP14 and vimentin by miR-320a inhibited GC cell proliferation, migration and invasion. miR-320a not only directly suppresses vimentin expression, but also binds to USP14, indirectly downregulating vimentin in GC tissues. 


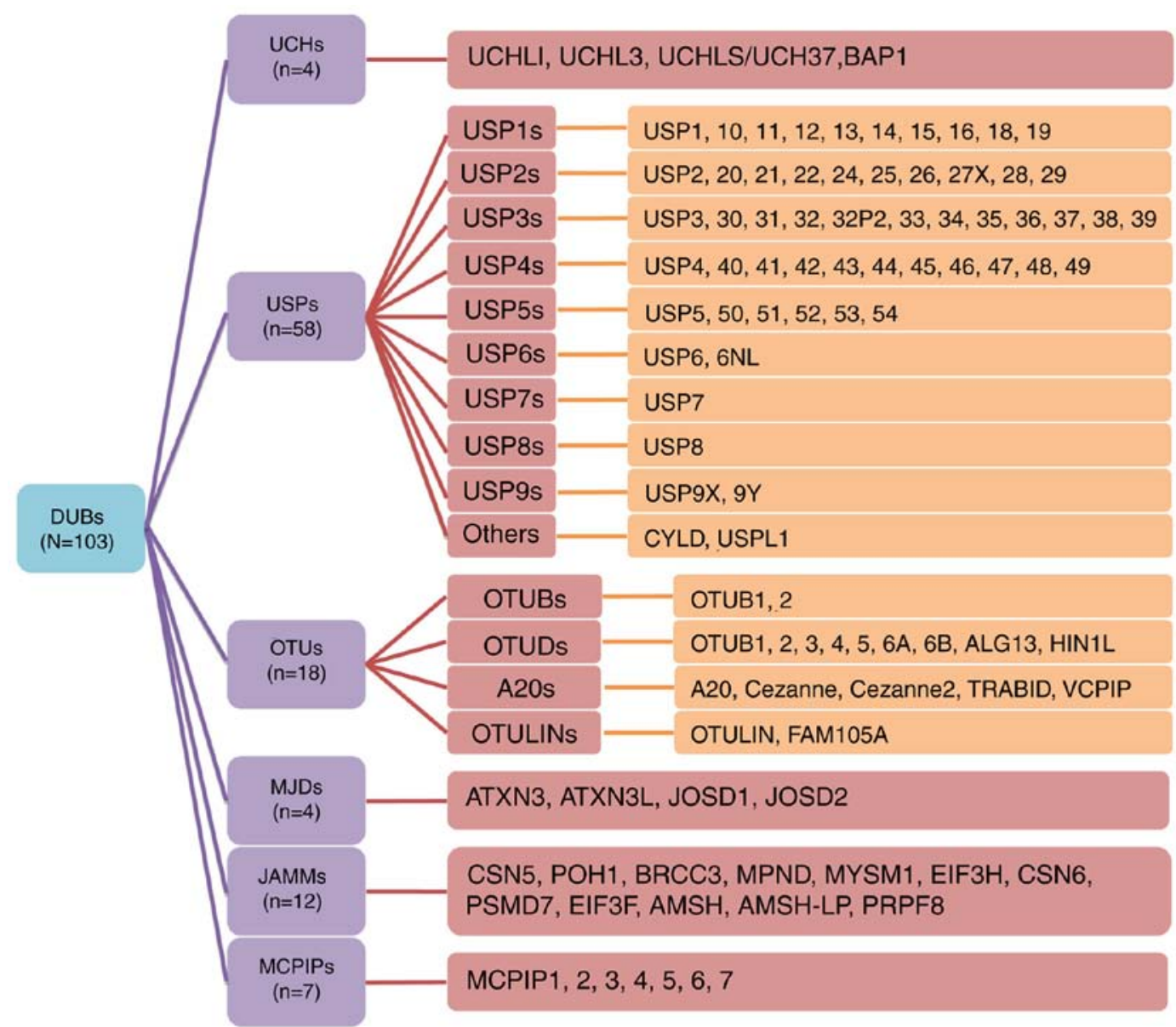

Figure 1. Members of the DUB family. The DUB family contains numerous members, which have been divided into subfamilies. The USPs are the largest subfamily of DUBs, and were further divided into 9 subfamilies (USP1-9) in the present study; CYLD lysine 63 deubiquitinase and USPL1 have been listed as other USP members. The first digits indicates the subfamily, for example, USP14 belongs to the USP1 subfamily. The subfamily classification of the ovarian tumor-related protease family refers to existing taxonomies (102). DUB, deubiquitinating enzyme; USP, ubiquitin-specific protease.

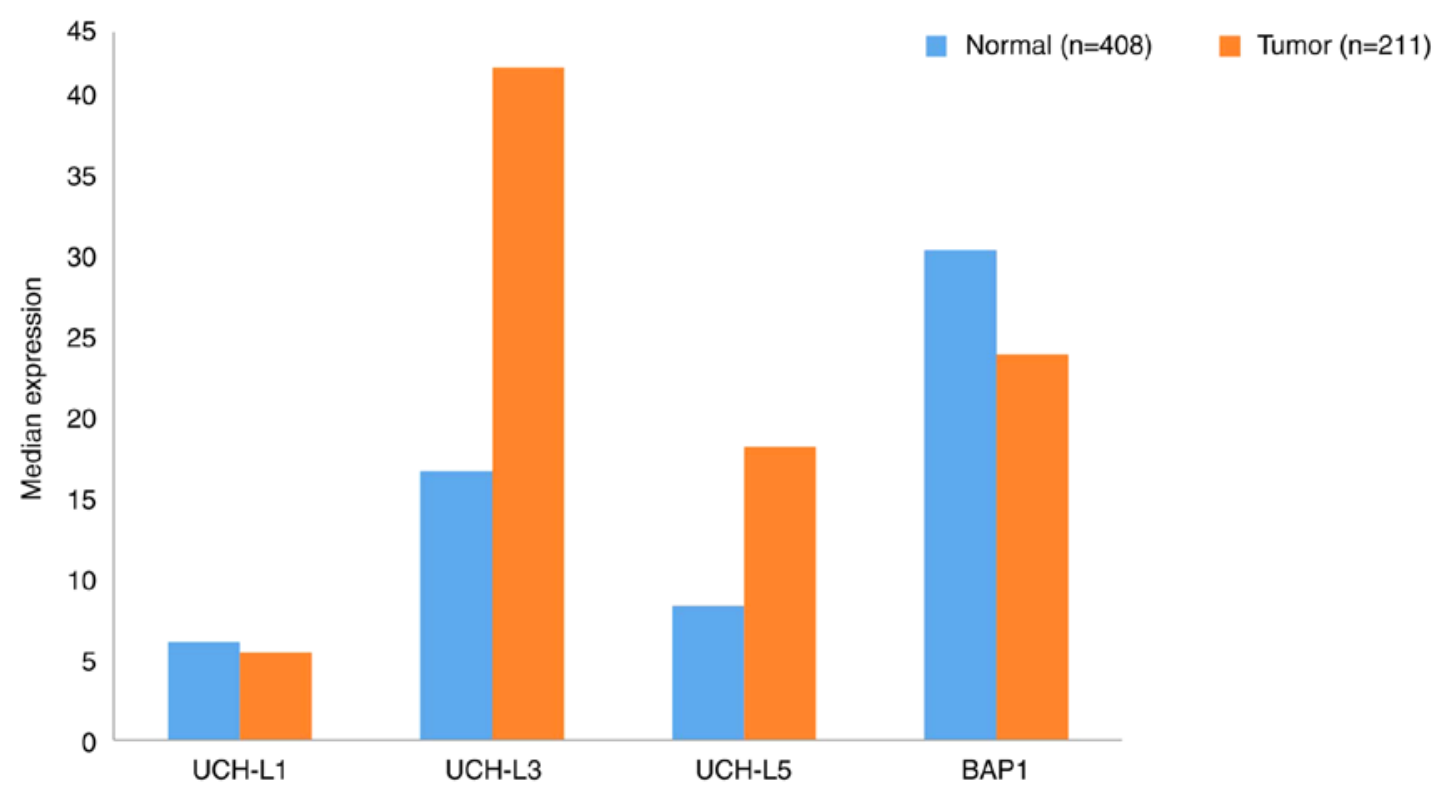

Figure 2. Gene expression profile of ubiquitin C-terminal hydrolases between gastric cancer samples and paired normal tissues. Data were extracted using the Gene Expression Profiling Interactive Analysis website. UCH, Ubiquitin C-terminal hydrolase; BAP1, BRCA1 associated protein-1.

Therefore, a high positive expression rate of USP14 correlates with a high recurrence rate in patients with GC $(44,45)$.
USP2 $s$ and $G C$. The 10 USP2 family members are: USP2 (47), USP20 (48), USP21 (49), USP22 (50), and USP24-29 (26,51-55). 


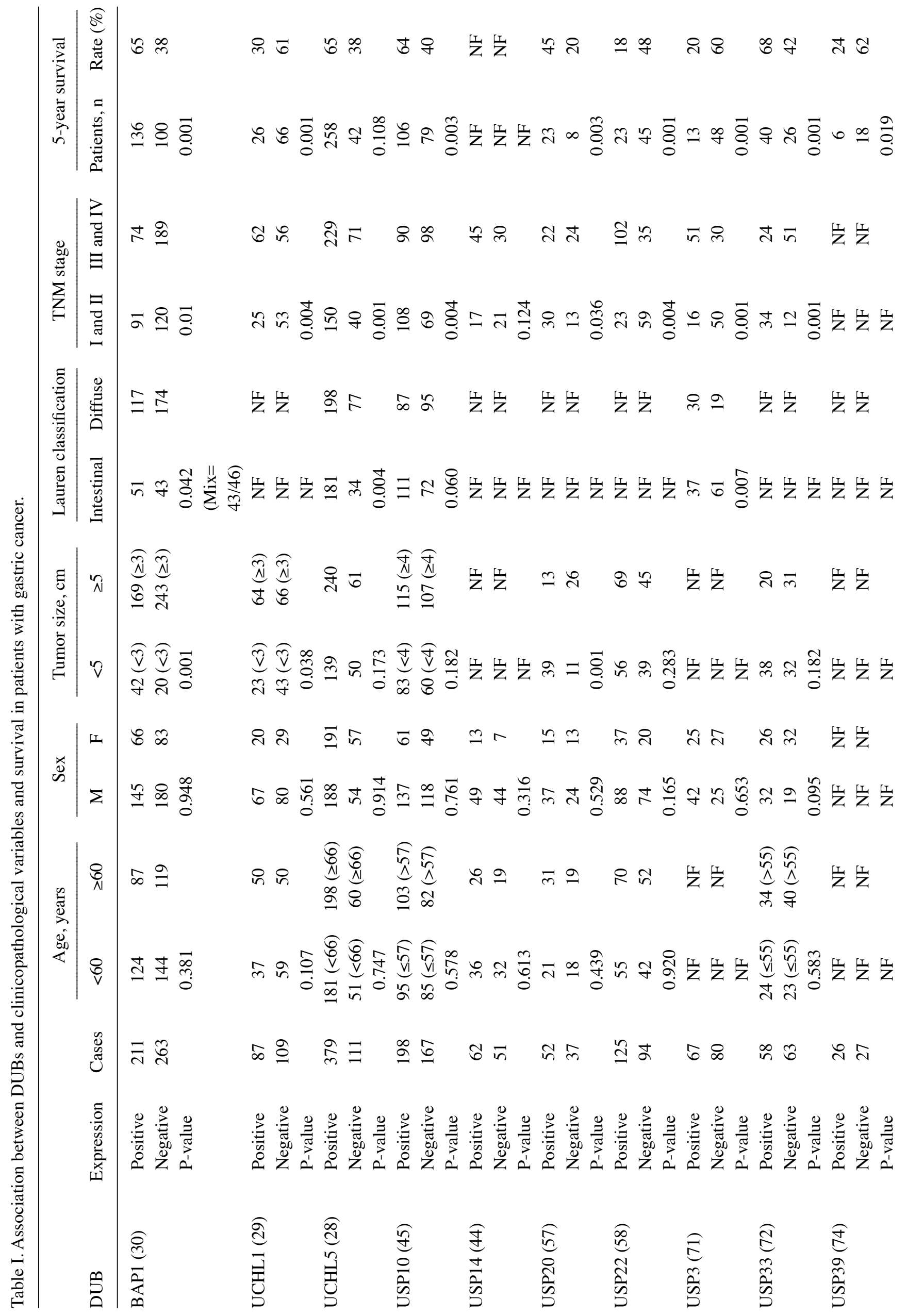




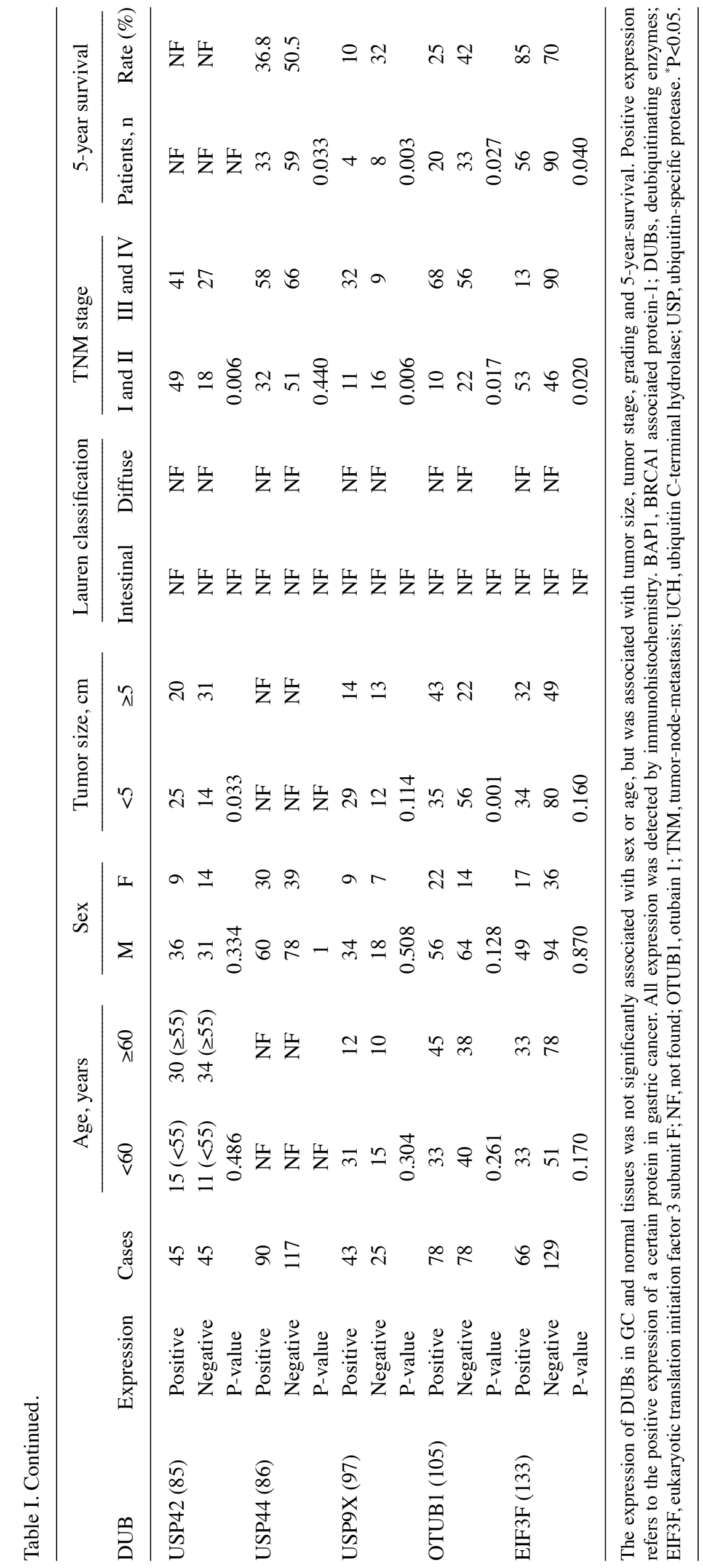




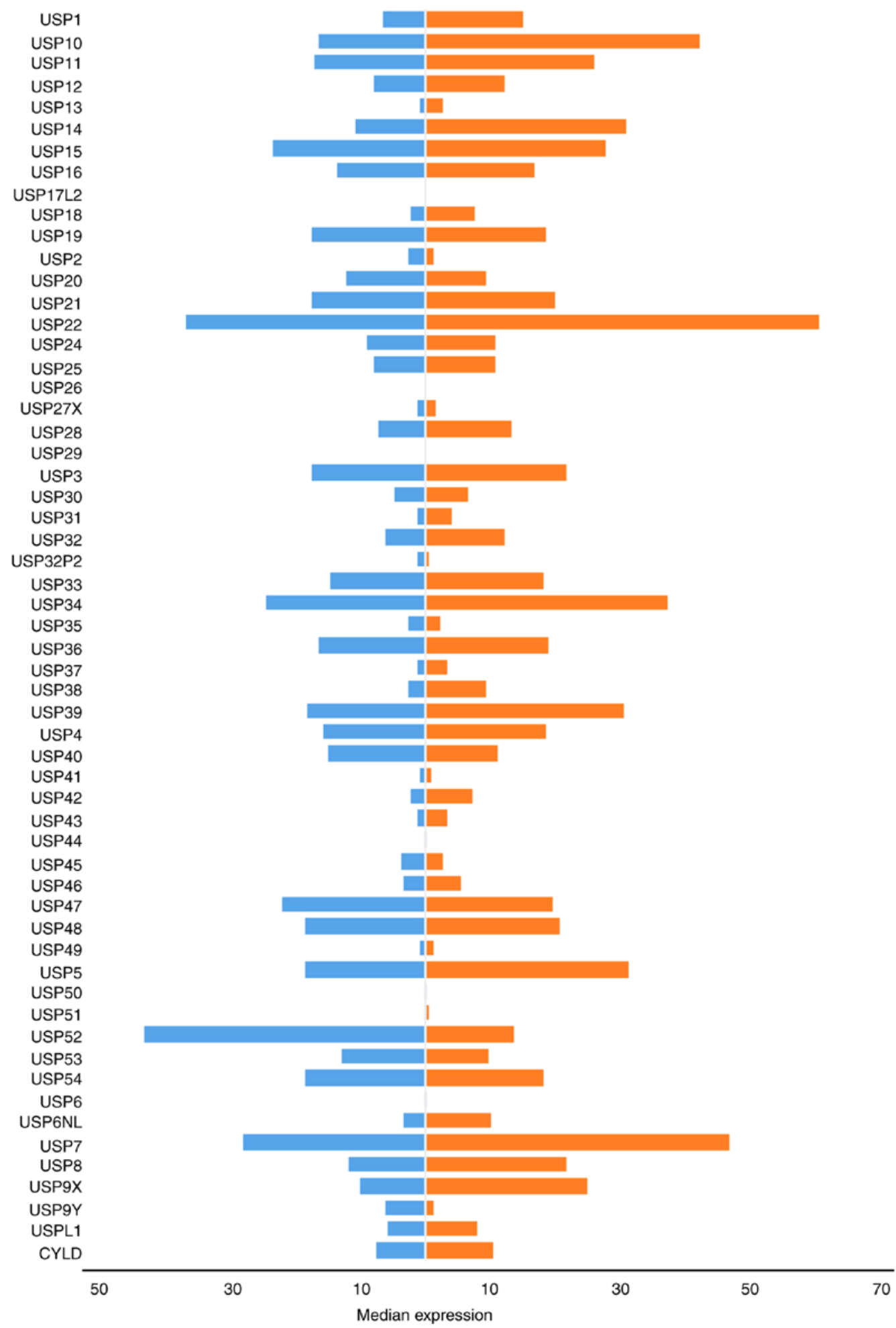

Figure 3. Gene expression profiles of ubiquitin-specific proteases between gastric cancer samples and paired normal tissues. Data were extracted using the Gene Expression Profiling Interactive Analysis website. USP, ubiquitin-specific protease. CYLD, CYLD lysine 63 deubiquitinase.

As depicted in Fig. 3, the protein expression level of the USP2 subfamily in GC tissues were typically higher compared with those in normal gastric tissues in $9 / 10$ cases, although the opposite was true for USP20. Notably, USP26 and 29 were not detected in gastric tissues, yet USP22 was expressed at levels as high as 60.31 TPM.
USP20, USP22 and USP28 have been previously determined to be associated with GC. Compared with normal tissues, high expression levels of USP28 were detected in GC tissues, and were also associated with the distant metastasis of tumors. Conversely, USP28 downregulation may significantly inhibit the proliferation and migration of GC cells; however, the 
effects of USP28 expression on the proliferation and migration of gastric epithelial mucosal cell lines were not significant (46). The aforementioned findings provide a novel insight for the development of therapeutic strategies to treat $\mathrm{GC}$ via the regulation of USP28 (56). USP20 also serves an important role in gastric tumorigenesis and progression. A negative association between USP20 expression and tumor size, tumor invasion and TNM stage has previously been reported (Table I). It was revealed that USP20 expression negatively correlated with patient prognosis and its anti-tumor activity. The mechanism underlying the effects of USP20 included the positive regulation of claspin stabilization in GC, thus, USP20 represents a promising molecular target for the development of novel therapeutic drugs (57). USP22-mediated protein stabilization of B cell-specific Moloney murine leukemia virus integration site 1 promotes the stemness of GC stem cells as well as GC progression, and its expression may also serve an important role in gastric carcinoma (58-60). Yang et al discussed that USP22 expresion is correlate with cancer progression. Where they found that around $57 \%$ of gastric cancer tisues showed high expression of USP22 comparing with normal connective tissue. This overexpression of USP22 consequentially effecct on tumor size, inavsion and metastasis (60). Additionally, both USP20 and USP22 expression are positively correlated with the 5-year survival rate of patients with GC $(57,60)$.

USP3s and GC. The USP3 subfamily represents the largest family of USPs and consists of the following 12 members: USP3 (61), USP 30 (62), USP31 (63,64), USP32, USP32P2 (22), USP33 (64), USP34 (65), USP35 (66), USP36 (67), USP37 (68), USP38 (69) and USP39 (70). As shown in Fig. 3, excluding USP32P2 and USP35, the expression of each member was upregulated in GC tissues compared with normal gastric tissues. The highest expression levels were exhibited by USP34 (37.21), while the lowest were reported for USP32P2 (0.33). The expression levels of USP30, USP31, USP32P2, USP35, USP37 and USP 38 were $<10$ TPM.

USP3 s may also serve as useful biomarkers to predict the prognosis of patients with GC. Studies investigating USP3s revealed their ability to influence cell proliferation, cell cycle regulation and transfer-related protein expression (61). In vivo experiments revealed that USP3s promoted the growth and metastasis of GC. Additionally, the high expression levels of these proteins imparted a lower survival rate in patients (71). Studies have also discovered that tumor location, tumor infiltration depth and TNM stage are all associated with USP33 upregulation, and affect the overall survival rate and prognosis of patients with GC. USP33 may also be linked with the prognosis of GC (62), and its high expression levels indicated longer survival times in patients (72).

It was also determined that short hairpin RNA-mediated downregulation of USP39, another member of the USP3 subfamily, inhibited GC cell proliferation and colony formation. USP39 inhibition also induced $\mathrm{G}_{2} / \mathrm{M}$ phase arrest and increased poly (ADP-ribose) polymerase cleavage (Asp214) suggesting that USP39 is critical for GC cell proliferation. As USP39 is upregulated in certain types of cancer, and hyperproliferation is a hallmark of cancer, USP39 may represent a potential therapeutic target for the treatment of several cancer types (73). By contrast, miR-133a expression was inversely correlated with USP39, which it directly targets by binding at the 3'-untranslated region; the high expression rate of USP39 indicated a longer survival time for patients (74).

USP4s and GC. The USP4 subfamily has a total of 11 members: USP4 (75), USP40 (76), USP41 (77), USP42 (78), USP43 (79), USP44, USP45 (80), USP46 (80), USP47 (80), USP48 (81) and USP49 (82). Generally, the expression of USP4 $\mathrm{s}$ in GC tissues was increased compared with those in normal adjacent tissues; however, USP40, USP44, USP45 and USP47 were downregulated (Fig. 3). The expression levels of the seven upregulated members were all $<10$.

Studies into GC have investigated USP42, USP44 and USP47. It has been reported that USP47 may represent a drug resistant target for GC. Additionally, it was determined that miR-204-5p was downregulated in GC, and may inhibit the proliferation of GC cells by targeting USP47 and RAB22A, thus serving a role in suppressing cancer development. Therefore, the recovery of miR-204-5p expression may be a potential therapeutic strategy for the treatment of GC $(83,84)$. In vitro analyses also demonstrated that USP42 silencing suppressed cell proliferation by inducing $\mathrm{G}_{0} / \mathrm{G}_{1}$ arrest, and inhibited cellular invasion via matrix metalloprotease and epithelial-mesenchymal transition regulation. The increased expression of USP42 may be important in tumor progression and the metastasis of $\mathrm{GC}$, and may serve as a prognostic marker (85). The combination of USP44 expression and DNA ploidy status may also serve as an independent prognostic marker in GC. Notably, the expression rate of USP44 in GC is negatively correlated with the 5-year survival rate of patients (86).

USP5s and GC. The USP5 subfamily comprises six members, including USP5 (87), USP50 (88), USP51 (89), USP52 (90), USP53 (91) and USP54 (92). The expression of USP5s in GC and normal tissues differed (Fig. 3). Notably, the expression of USP52 in CG tissues was upregulated 3-fold compared with that in normal gastric tissues, and USP52 was differentially expressed compared with USP5. The expression levels of USP50 and USP51 were $<1$ in normal and gastric tumor tissues, and although USP5s have been associated with multiple cancer types (93), no studies have reported the association between USP5s and GC.

USP6s and GC. At present, the USP6 subfamily comprises only two members, USP6 (94) and USP6NL (15). As presented in Fig. 3, the two members, particularly USP6, were not highly expressed in either GC or normal tissues. However, USP6 has been reported to contribute to the progression of colon cancer and may therefore represent a valuable prognostic biomarker for patients. USP6NL (also known as RN-tre) is a GTPase-activating protein involved in the regulation of endocytosis and signal transduction. USP6NL upregulation results in increased glycolysis in breast cancer cells and highlights a point of metabolic vulnerability for the targeting of certain therapeutic agents in a subset of aggressive basal-like breast tumors. The association between the USP6 subfamily and GC progression requires further investigation $(15,95)$.

USP7s and GC. USP7 is currently the only member of the USP7 subfamily. Its expression levels in GC tissues are 
higher than those in normal tissue (46.63 TPM and 28.04 TPM, respectively; Fig. 3). Studies investigating USP7 and its relation to GC are yet to be performed; however, H. pylori was reported to affect the expression of the USP family via alternative $H$. pylori-specific mechanisms distinct from the conserved signaling pathways, during the activation of the innate immune response (18).

USP8s and GC. The roles of USP8 and its substrate (epidermal growth factor) have been evaluated in cancer therapy, and their possible targeting for the treatment of Cushing's disease has been investigated (96); USP8 is the only member of the USP8 subfamily. As shown in Fig. 3, USP8 expression in GC tissues was increased $\sim 2$-fold compared with that in normal tissues.

USP9s and GC. The USP9 subfamily comprises two members, USP9X and Y. As presented in Fig. 3, the expression of USP9X in GC tissues was upregulated 2-fold compared with that of normal tissues. By contrast, the expression of USP9Y in normal tissues was higher than that of cancerous tissues, though its overall expression was notably lower than that of USP9X. Upregulation of the deubiquitinating enzyme USP9X in GC suggested that it may be associated with certain oncogenes, and it was also significantly associated with reduced survival rate (97). A link between USP9Y and GC has not yet been confirmed, although its expression has been revealed to correlate with certain breast cancer characteristics (98).

Other proteins and GC. Additional USP family members include CYLD lysine 63 deubiquitinase (CYLD) and USPL1. Their expression in GC tissues was notably increased compared with normal tissues (Fig. 3). The CYLD signaling pathway serves a biological function similar to that of the oncogenes in gastrointestinal tumors, and has been associated with the occurrence and development of GC $(99,100)$. Moreover, genetic variations affecting USPL1 expression have been linked to breast cancer (101).

Analysis of USP gene expression in GC and normal tissues (Fig. 3) revealed that their expression in tumor tissues is markedly upregulated compared with that in normal tissues; the majority of GC and normal tissues exhibited detectable basal levels of USP expression. Of note, the expression of certain genes was upregulated $>2$-fold; increased expression of USP52 (tumor=43.5; normal=13.6) was reported in normal tissues compared with GC samples. However, whether USPs may be considered as reliable prognostic indicators of GC requires further investigation. As presented in Table I, associations between USPs, and the clinicopathological features and prognosis of GC were reported. In addition, the increased expression of the majority of USPs in GC tissues was associated with poor prognosis. It was also revealed that the expression profiles of USP10, USP20 and USP33 were the opposite of those aforementioned.

\section{OTUs and GC}

A total of 18 OTU family DUBs exist in humans, the majority of which have been associated with the prognosis of patients with tumors. OTUs can be divided into four categories: OTUBs, OTUDs, A20s and OTULINs (102). The gene expression profiles of OTUs in GC samples and paired normal tissues ware presented in Fig. 4.

$O T U B s$ and $G C$. The OTUB family comprises two members, OTUB1 (103) and OTUB2 (104), which are expressed in the majority of tissues. In the present study, their expression was determined to be increased 2-fold compared with that of normal tissues. Additionally, the expression of OTUB1 in gastric tissues was markedly higher than that of OTUB2 (which was almost undetectable), yet the expression levels of OTUB1 in GC tissues were as high as 93.09, which was twice that exhibited in normal tissues (Fig. 4). OTUB1-isoform 2 was reported to be a predictor of poor prognosis and to promote tumor progression in patients with GC (95). However, its potential clinical application as a marker of tumor invasiveness requires further investigation. Poor prognosis of patients with GC was revealed to correlate with high expression of OTUB1-isoform 2 (105); the association between OTUB2 and GC remains to be further studied.

OTUDs and GC. OTUDs are the largest class of DUBs, which comprises the following nine members: OTUD1-5 (106-110), OTUD6A (111) and B (112), UDP-N-acetylglucosamine transferase subunit ALG13 homolog (ALG13) and hematological and neurological expressed 1 protein (HIN1 L) (102). Using data extracted from GEPIA, the expression levels of both of the OTUD subfamily members in GC and normal tissues were determined to be relatively low. OTUD6A and HIN1L were undetectable, although the expression levels of OTUD4 and OTUD5 were $>10$ in GC tissues. Further investigation is required to determine the pathophysiological role of OTUDs in GC progression.

A20s and GC. The A20 subfamily contains five members: A20, Cezanne (113), Cezanne2 (114), Ubiquitin thioesterase ZRANB1 (TRABID) (115) and ubiquitinating protein VCIP135 (VCPIP) (102). As exhibited in Fig. 4, the expression of VCPIP in GC and normal tissues was notably high, yet low expression levels of other A20s were detected. Additionally, to the best of our knowledge, no data regarding the expression of TRABID has yet been reported. Inhibition of A20 expression or overexpression of miR-200a may prevent the polydiallylation of receptor interacting serine/threonine kinase 1 , and promote caspase- 8 lysis and tumor necrosis factor-related apoptosis inducing ligand-associated apoptosis (102). A20 is able to induce apoptosis in GC cells, thus may be considered as a potential therapeutic target for GC (116). In the current study, the expression levels of A20s in GC tissues were not high, yet notable levels of VCPIP were detected, suggesting that further study into the prognostic value of A20s in GC is required.

OTULINs and GC. The OTULIN subfamily comprises only two members, OTULIN and FAB105A (102). The role of OTULIN in immune homeostasis and inflammation has been reported to result in certain autoimmune and cancer-associated defects (117). Data analysis in the present study indicated that OTULIN and FAB105A expression in GC tissues was increased compared with that in normal tissues; however, the levels of expression remained low (Fig. 4). Conversely, the 


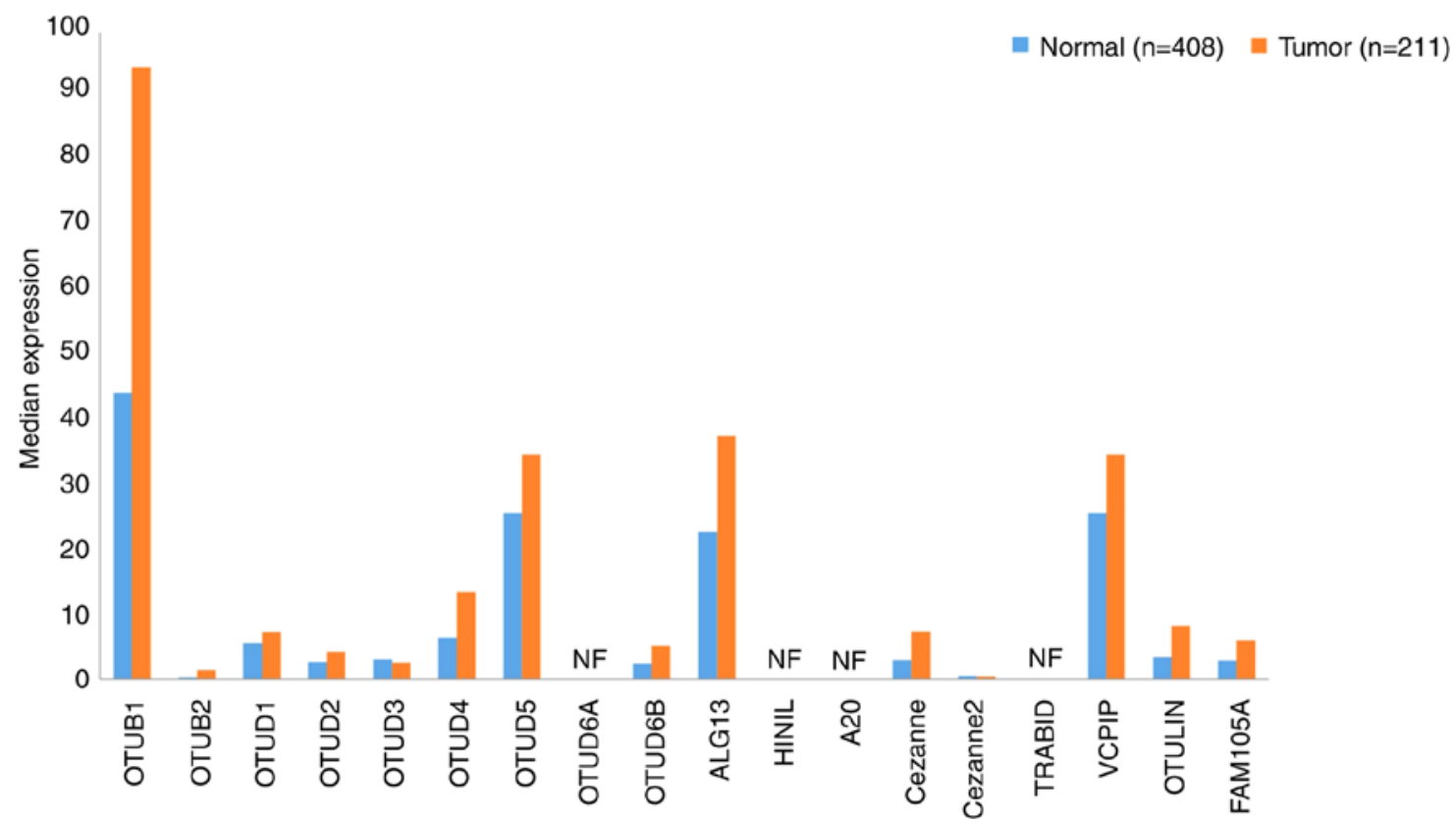

Figure 4. Gene expression profiles of ovarian tumor-related proteases between gastric cancer samples and paired normal tissues. Data were extracted using the Gene Expression Profiling Interactive Analysis website. NF, not found.

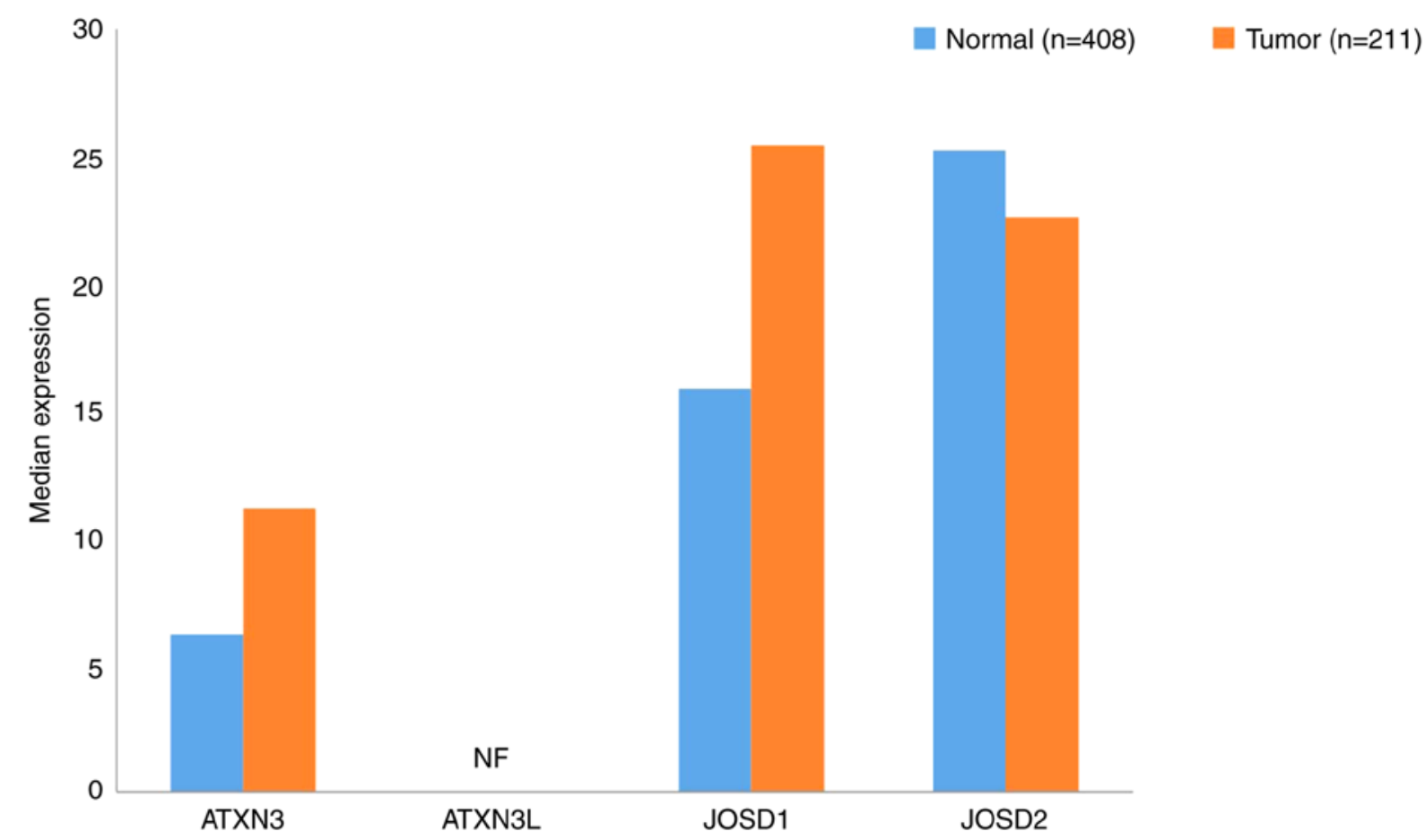

Figure 5. Gene expression profiles of Machado-Joseph disease protein domain proteases between gastric cancer samples and paired normal tissues. Data were extracted using the Gene Expression Profiling Interactive Analysis website. NF, not found. ATXN, ataxin; JOSD, Josephin domain containing.

expression levels of OTUB1, OTUD5, ALG13 and VCPIP were markedly increased. In particular, OTUB1 expression in GC tissues was 93.09 , which is $>2$-fold higher than the expression level observed in healthy tissues. Moreover, certain studies have revealed that the high expression rate of OTUB1 in GC tissues was associated with poor prognosis $(105,118)$. The association between the prognosis of patients with GC and the expression of other members of the OTU subfamily remains unclear; thus further investigation is required.

\section{MJDs and GC}

Ataxin (ATXN)3, ATXN3L, Josephin domain containing (JOSD)1 (119) and JOSD2 (120) all belong to the MJD subfamily. In the present study, JOSD1 and 2 were revealed to be expressed in both GC and normal tissues; however, the expression of ATXN3L was not detected (Fig. 5). The expression levels of ATXN3 and JOSD1 in GC tissues were increased compared with normal tissues. Notably, the expression level of JOSD2 was downregulated 


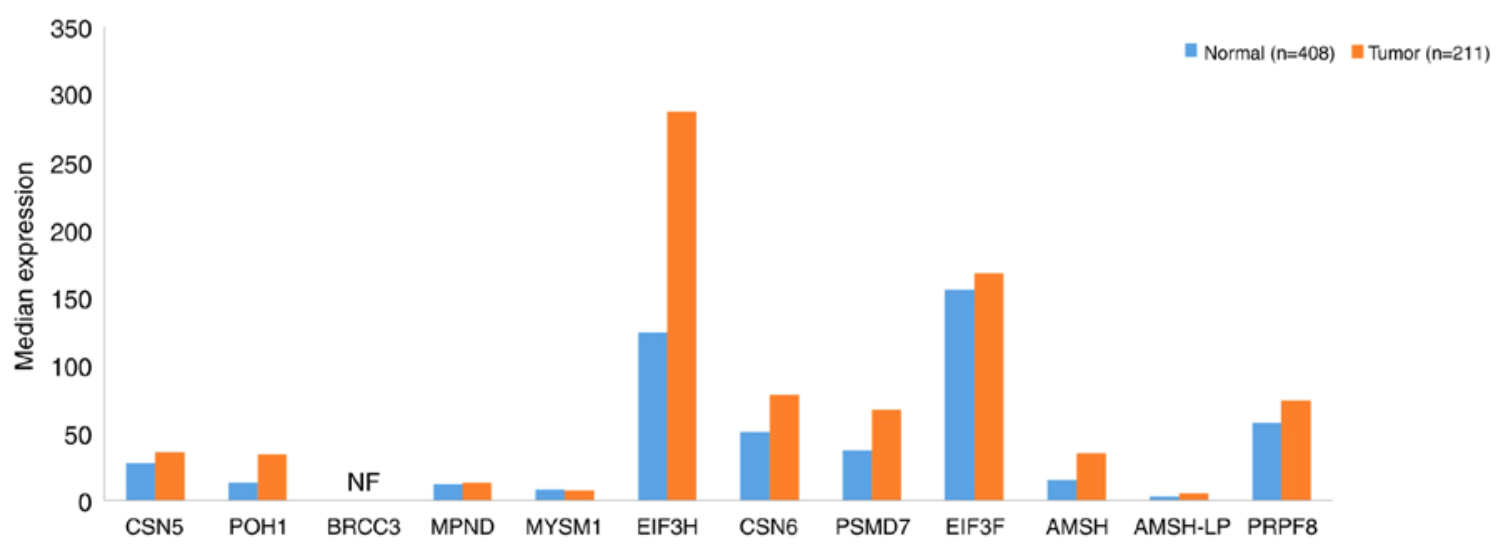

Figure 6. Gene expression profiled of the Jab1/MPN domain-associated metalloisopeptidases between gastric cancer samples and paired normal tissues. Data were extracted using the Gene Expression Profiling Interactive Analysis website. NF, not found.

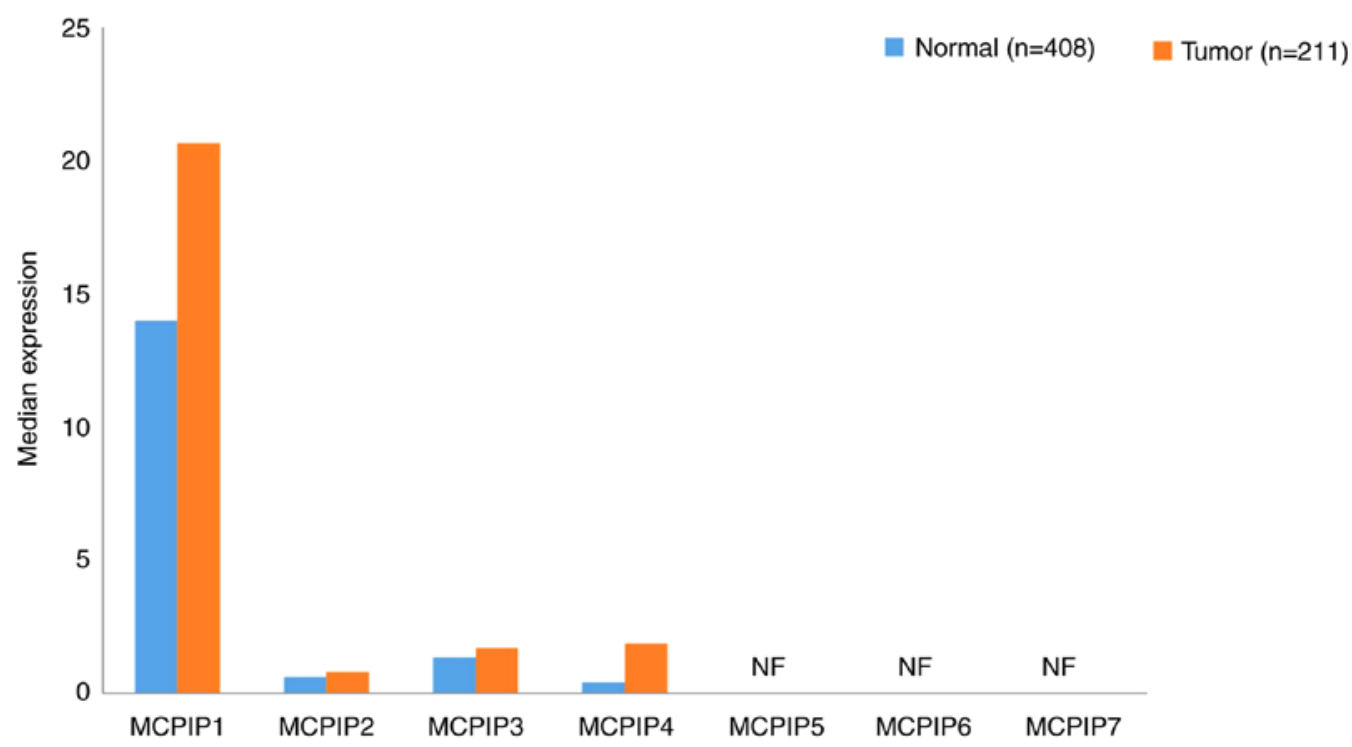

Figure 7. Gene expression profiles of monocyte chemotactic protein-induced proteins between gastric cancer samples and paired normal tissues. Data were extracted using the Gene Expression Profiling Interactive Analysis website. NF, not found. MCPIP, monocyte chemotactic protein-induced proteins.

in GC samples. Furthermore, the expression of ATXN3 in GC was determined to be associated with tumor cell proliferation and infiltration (121). Therefore, the association between MJDs and the prognosis of patients with GC requires further analysis.

\section{JAMMs and GC}

The JAMM subfamily comprises 12 members, including COP9 signalsome subunit (CSN)5, 26S proteasome non-ATPase regulatory subunit 14 (POH1) (122), BRCA1/BRCA2-containing complex subunit 3 (BRCC3) (123), MPN domain containing (MPND) (124), myb-like SWIRM and MPN domains 1 (MYSM1) (125), eukaryotic translation initiation factor 3 subunit (EIF3)H, CSN6 (126), 26S proteasome non-ATPase regulatory subunit 7 (PSMD7) (127), EIF3F, anti-Müllerian hormone (AMSH) (128), AMSH-LP (129) and pre-mRNA-processing-splicing factor 8 (PRPF8) (130). The data presented in Fig. 6 demonstrate that the expression levels of JAMMs in GC tissues were upregulated compared with those in normal tissues, particularly EIF3H and EIF3F, in which the expression levels were $>120$. The expression of BRCC3 was not detected. These findings suggest that the inhibition of CSN5 may result in a significant increase in p53 levels, indicating that CSN5 may be a crucial regulator of p53 and its associated intracellular signaling pathway, via CSN5-mediated cell activity.

Moreover, upregulation of CSN5 has been significantly associated with the progression of GC; therefore, CSN5 may represent a novel target for the treatment of this disease (131). EIF3H was also reported to influence the progression of GC (132), and therefore, may serve as a potential therapeutic target. In particular, the strategy of inhibiting EIF3H expression may suppress the progression of GC and improve patient prognosis (131). Furthermore, EIF3F was determined to serve an important role in the recurrence of GC; increased expression rates of EIF3F in GC were associated with higher 5-year survival rates of patients (133).

\section{MCPIPs and GC}

The MCPIP subfamily includes MCPIP1 (134), MCPIP2-4 (135), MCPIP5 (136), MCPIP6 and 7 (137). The expression data of the MCPIP subfamily in GC and normal tissues are presented in Fig. 7. MCPIPs were expressed at markedly low levels in GC 

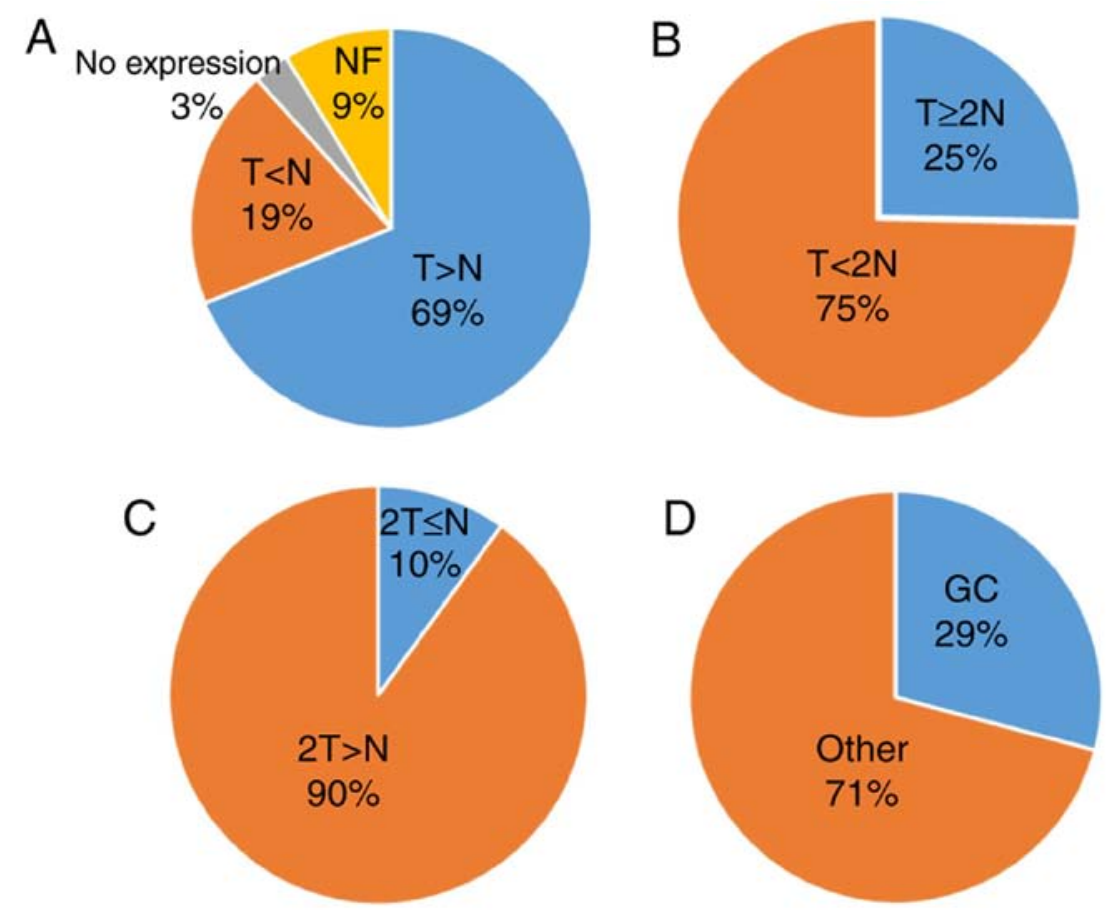

Figure 8. Expression of DUBs in GC. Data were extracted using the Gene Expression Profiling Interactive Analysis website. (A) $T>N(n=71)$; $T<N$ ( $n=20)$; Not expressed $(n=3) ; N F(n=9)$. No data found for $T=N \neq 0$. (B) $T \geq 2 N(n=18)$. (C) $2 T \leq N(n=2)$. (D) GC-related DUBs $(n=30)$. AMSH, anti-Müllerian hormone; BAP1, BRCA1 associated protein-1; DUBs, DUB, deubiquitinating enzymes; EIF3, eukaryotic translation initiation factor 3 subunit; FAB105A, family with sequence similarity 105 member A; GC, gastric cancer; JOSD, Josephin domain containing; MCPIP, monocyte chemotactic protein-induced proteins; OUT, ovarian tumor-related protease; PRPF8, pre-mRNA-processing-splicing factor 8; UCH, ubiquitin C-terminal hydrolase; USP, ubiquitin-specific protease.

and normal tissues; and only MCPIP1 was expressed at levels $>10$. It has been demonstrated that MCPIP3 serves a negative role in the migration of human colorectal cancer cells (138). In the same study, researchers demonstrated that overexpression of MCPIP3 inhibit cell migration, which confirmed by downregulation of E-cadherin (Marker of EMT). Alternately, mutated MCPIP3 was responsible for enhancing cancer cell migration; However, MCPIP3 expression could not inhibit the cell growth and proliferation (138). Though none of the MCPIP family members were determined to be associated with the 5-year survival rate of patients with GC. In addition, the expression profiles of MCPIP5-7 in GC and normal tissues have not yet been determined. Therefore, the association between MCPIPs and GC should be further evaluated in the future.

\section{Conclusions and future perspectives}

According to global cancer statistics in 2018 (125), 18.1 million new cancer cases and 9.6 million cancer-associated mortalities were reported worldwide, and the incidence of GC was ranked sixth; the incidence of GC was 5.7\% (18.1 million) and the mortality rate was $8.2 \%$ (9.6 million) of the total cancer cases. Furthermore, the incidence of GC in males was $7.2 \%$ (9.5 million), and the mortality rate was $9.5 \%$ (5.4 million), compared with an incidence of $4.1 \%$ (8.6 million) and mortality rate of $6.5 \%$ (4.2 million) in female patients (139). The high prevalence and mortality rates suggest that novel therapeutic strategies are required to treat this disease. The present review focused on the association between GC and DUBs. The present study reported that DUBs are typically upregulated in the majority of GC tissues (79\%). A total of 25\% of the reported GC cases exhibited $a \geq 2$-fold increase in DUB expression compared with that of normal tissues. Only $19 \%$ of healthy tissues exhibited enhanced USP32P2 and USP52 expression, in which this expression was twice the level of that in GC tissues (Fig. 8D). Notably, USP17L2, USP26 and USP29 expression was detected in both GC and normal tissues.

On the contrary, the number of DUBs associated with GC was determined to be $29 \%$. Following analysis of data from previously published studies (Table I), the expression of DUBs in GC and normal tissues was not determined to be associated with either sex or age; however, an association between DUBs and tumor size, classification and staging was observed. In addition, the expression level of DUBs was significantly associated with the 5-year survival rate of patients with GC. Among the upregulated genes in GC, six DUBs were linked to a high 5-year survival rate, though the difference between the two was not significant. Thus, DUBs may serve a dual role in the prognosis of GC. However, further investigation is required. Providing that DUBs can be divided into two categories according to the prognosis of $\mathrm{GC}$, the common features associated with this disease and DUBs may be identified, in which DUBs may be considered in the development of treatments for GC.

\section{Acknowledgements}

Not applicable.

\section{Funding}

No funding was received. 


\section{Availability of data and materials}

The datasets used and/or analyzed during the current study are available from the corresponding author on reasonable request.

\section{Authors' contributions}

JS, XS and YG conducted literature searching and wrote this review. JS conducted the data analysis. The language of the review was edited by MAAM.

\section{Ethics approval and consent to participate}

Not applicable.

\section{Patient consent for publication}

Not applicable.

\section{Competing interests}

The authors declare that they have no competing interests.

\section{References}

1. Pidsley R, Lawrence MG, Zotenko E, Niranjan B, Statham A Song J, Chabanon RM, Qu W, Wang H, Richards M, et al: Enduring epigenetic landmarks define the cancer microenvironment. Genome Res 28: 625-638, 2018.

2. Zentner GE and Henikoff S: High-resolution digital profiling of the epigenome. Nat Rev Genet 15: 814-827, 2014.

3. Onder O, Sidoli S, Carroll M and Garcia BA: Progress in epigenetic histone modification analysis by mass spectrometry for clinical investigations. Expert Rev Proteomics 12: 499-517, 2015.

4. Swatek KN and Komander D: Ubiquitin modifications. Cell Res 26: 399-422, 2016.

5. Rogov V, Dotsch V, Johansen T and Kirkin V: Interactions between autophagy receptors and ubiquitin-like proteins form the molecular basis for selective autophagy. Mol Cell 53: 167-178, 2014.

6. Hershko A: Ubiquitin: Roles in protein modification and breakdown. Cell 34: 11-12, 1983.

7. Pickart CM: Mechanisms underlying ubiquitination. Annu Rev Biochem 70: 503-533, 2001.

8. Hershko A and Ciechanover A: The ubiquitin system. Annu Rev Biochem 67: 425-479, 1998.

9. Finley D, Ciechanover A and Varshavsky A: Ubiquitin as a central cellular regulator. Cell 116 (Suppl 2): S29-S32, 2004.

10. Zhou MJ, Chen FZ and Chen HC: Ubiquitination involved enzymes and cancer. Med Oncol 31: 93, 2014.

11. Johnston SC, Riddle SM, Cohen RE and Hill CP: Structural basis for the specificity of ubiquitin C-terminal hydrolases. EMBO J 18: 3877-3887, 1999.

12. Fang $Y$ and Shen $X$ : Ubiquitin carboxyl-terminal hydrolases: Involvement in cancer progression and clinical implications. Cancer Metastasis Rev 36: 669-682, 2017.

13. McDonough M, Sangan P and Gonda DK: Characterization of novel yeast RAD6 (UBC2) ubiquitin-conjugating enzyme mutants constructed by charge-to-alanine scanning mutagenesis. J Bacteriol 177: 580-585, 1995.

14. Xu JC, Dawson VL and Dawson TM: Usp16: Key controller of stem cells in Down syndrome. EMBO J 32: 2788-2789, 2013.

15. Avanzato D, Pupo E, Ducano N, Isella C, Bertalot G, Luise C, Pece S, Bruna A, Rueda OM, Caldas C, et al: High USP6NL levels in breast cancer sustain chronic AKT phosphorylation and GLUT1 stability fueling aerobic glycolysis. Cancer Res 78: 3432-3444, 2018.

16. Weber A, Elliott PR, Pinto-Fernandez A, Bonham S, Kessler BM, Komander D, El Oualid F and Krappmann D: A linear diubiquitin-based probe for efficient and selective detection of the deubiquitinating enzyme OTULIN. Cell Chem Biol 24: 1299-1313.e7, 2017.
17. Taneera J, Fadista J, Ahlqvist E, Atac D, Ottosson-Laakso E, Wollheim CB and Groop L: Identification of novel genes for glucose metabolism based upon expression pattern in human islets and effect on insulin secretion and glycemia. Hum Mol Genet 24: 1945-1955, 2015.

18. Coombs N, Sompallae R, Olbermann P, Gastaldello S, Goppel D, Masucci MG and Josenhans C: Helicobacter pylori affects the cellular deubiquitinase USP7 and ubiquitin-regulated components TRAF6 and the tumour suppressor p53. Int J Med Microbiol 301: 213-224, 2011.

19. Saldana M, VanderVorst K, Berg AL, Lee H and Carraway KL: Otubain 1: A non-canonical deubiquitinase with an emerging role in cancer. Endocr Relat Cancer 26: R1-R14, 2019.

20. Rahman R, Asombang AW and Ibdah JA: Characteristics of gastric cancer in Asia. World J Gastroenterol 20: 4483-5890, 2014.

21. Torre LA, Bray F, Siegel RL, Ferlay J, Lortet-Tieulent J and Jemal A: Global cancer statistics, 2012. CA Cancer J Clin 65: 87-108, 2015

22. Tang Z, Li C, Kang B, Gao G, Li C and Zhang Z: GEPIA: A web server for cancer and normal gene expression profiling and interactive analyses. Nucleic Acids Res 45: W98-W102, 2017.

23. Todi SV and Paulson HL: Balancing act: Deubiquitinating enzymes in the nervous system. Trends Neurosci 34: 370-382, 2011.

24. Fang Y, Fu D and Shen XZ: The potential role of ubiquitin c-terminal hydrolases in oncogenesis. Biochim Biophys Acta 1806: 1-6, 2010.

25. Kim HJ, Kim YM, Lim S, Nam YK, Jeong J, Kim HJ and Lee KJ: Ubiquitin C-terminal hydrolase-L1 is a key regulator of tumor cell invasion and metastasis. Oncogene 28: 117-127, 2009.

26. Dang LC, Melandri FD and Stein RL: Kinetic and mechanistic studies on the hydrolysis of ubiquitin C-terminal 7-amido-4-methylcoumarin by deubiquitinating enzymes. Biochemistry 37: 1868-1879, 1998.

27. Case A and Stein RL: Mechanistic studies of ubiquitin C-terminal hydrolase L1. Biochemistry 45: 2443-2452, 2006.

28. Arpalahti L, Laitinen A, Hagström J, Mustonen H, Kokkola A, Böckelman C, Haglund C and Holmberg CI: Positive cytoplasmic UCHL5 tumor expression in gastric cancer is linked to improved prognosis. PLoS One 13: e0193125, 2018.

29. Gu YY, Yang M, Zhao M, Luo Q, Yang L, Peng H, Wang J, Huang SK, Zheng ZX, Yuan XH, et al: The de-ubiquitinase UCHL1 promotes gastric cancer metastasis via the Akt and Erk1/2 pathways. Tumour Biol 36: 8379-8387, 2015.

30. Yan S, He F, Luo R, Wu H, Huang M, Huang C, Li Y and Zhou Z: Decreased expression of BRCA1-associated protein 1 predicts unfavorable survival in gastric adenocarcinoma. Tumour Biol 37: 6125-6133, 2016

31. Nijman SM, Luna-Vargas MP, Velds A, Brummelkamp TR, Dirac AM, Sixma TK and Bernards R: A genomic and functional inventory of deubiquitinating enzymes. Cell 123: 773-786, 2005.

32. Das DS, Das A, Ray A, Song Y, Samur MK, Munshi NC, Chauhan D and Anderson KC: Blockade of deubiquitylating enzyme USP1 inhibits DNA repair and triggers apoptosis in multiple myeloma cells. Clin Cancer Res 23: 4280-4289, 2017.

33. Kedersha N, Panas MD, Achorn CA, Lyons S, Tisdale S, Hickman T, Thomas M, Lieberman J, McInerney GM, Ivanov P and Anderson P: G3BP-Caprin1-USP10 complexes mediate stress granule condensation and associate with $40 \mathrm{~S}$ subunits. J Cell Biol 212: 845-860, 2016.

34. Kapadia B, Nanaji NM, Bhalla K, Bhandary B, Lapidus R, Beheshti A, Evens AM and Gartenhaus RB: Fatty Acid Synthase induced S6Kinase facilitates USP11-eIF4B complex formation for sustained oncogenic translation in DLBCL. Nat Commun 9: 829,2018

35. Aron R, Pellegrini P, Green EW, Maddison DC, Opoku-Nsiah K, Wong JS, Daub AC, Giorgini F and Finkbeiner S: Publisher correction: Deubiquitinase Usp12 functions noncatalytically to induce autophagy and confer neuroprotection in models of Huntington's disease. Nat Commun 9: 4333, 2018.

36. Zhang S, Zhang M, Jing Y, Yin X, Ma P, Zhang Z, Wang X, Di W and Zhuang G: Deubiquitinase USP13 dictates MCL1 stability and sensitivity to BH3 mimetic inhibitors. Nat Commun 9: 215, 2018.

37. Lee BH, Lee MJ, Park S, Oh DC, Elsasser S, Chen PC, Gartner C, Dimova N, Hanna J, Gygi SP, et al: Enhancement of proteasome activity by a small-molecule inhibitor of USP14. Nature 467: 179-184, 2010. 
38. Eichhorn PJ, Rodon L, Gonzalez-Junca A, Dirac A, Gili M, Martinez-Saez E, Aura C, Barba I, Peg V, Prat A, et al: USP15 stabilizes TGF- $\beta$ receptor I and promotes oncogenesis through the activation of TGF- $\beta$ signaling in glioblastoma. Nat Med 18: 429-435, 2012.

39. Adorno M, Sikandar S, Mitra SS, Kuo A, Nicolis Di Robilant B, Haro-Acosta V, Ouadah Y, Quarta M, Rodriguez J, Qian D, et al: Usp16 contributes to somatic stem-cell defects in Down's syndrome. Nature 501: 380-384, 2013.

40. Shaw JA, Page K, Blighe K, Hava N, Guttery D, Ward B, Brown J, Ruangpratheep C, Stebbing J, Payne R, et al: Genomic analysis of circulating cell-free DNA infers breast cancer dormancy. Genome Res 22: 220-231, 2012.

41. Malakhov MP, Malakhova OA, Kim KI, Ritchie KJ and Zhang DE: UBP43 (USP18) specifically removes ISG15 from conjugated proteins. J Biol Chem 277: 9976-9981, 2002.

42. Combaret L, Adegoke OA, Bedard N, Baracos V, Attaix D and Wing SS: USP19 is a ubiquitin-specific protease regulated in rat skeletal muscle during catabolic states. Am J Physiol Endocrinol Metab 288: E693-E700, 2005.

43. Xie L, Wei J, Qian X, Chen G, Yu L, Ding Y and Liu B: CXCR4, a potential predictive marker for docetaxel sensitivity in gastric cancer. Anticancer Res 30: 2209-2216, 2010.

44. Fu Y, Ma G, Liu G, Li B, Li H, Hao X and Liu L: USP14 as a novel prognostic marker promotes cisplatin resistance via Akt/ERK signaling pathways in gastric cancer. Cancer Med 7: 5577-5588, 2018

45. Zeng Z, Wu HX, Zhan N, Huang YB, Wang ZS, Yang GF, Wang $\mathrm{P}$ and Fu GH: Prognostic significance of USP10 as a tumor-associated marker in gastric carcinoma. Tumour Biol 35 3845-3853, 2014

46. Zhu Y, Zhang Y, Sui Z, Zhang Y, Liu M and Tang H: USP14 de-ubiquitinates vimentin and miR-320a modulates USP14 and vimentin to contribute to malignancy in gastric cancer cells. Oncotarget 8: 48725-48736, 2017.

47. Renatus M, Parrado SG, D'Arcy A, Eidhoff U, Gerhartz B, Hassiepen U, Pierrat B, Riedl R, Vinzenz D, Worpenberg S and Kroemer M: Structural basis of ubiquitin recognition by the deubiquitinating protease USP2. Structure 14: 1293-1302, 2006.

48. Berthouze M, Venkataramanan V, Li Y and Shenoy SK: The deubiquitinases USP33 and USP20 coordinate beta2 adrenergic receptor recycling and resensitization. EMBO J 28: 1684-1796, 2009.

49. Ye Y, Akutsu M, Reyes-Turcu F, Enchev RI, Wilkinson KD and Komander D: Polyubiquitin binding and cross-reactivity in the USP domain deubiquitinase USP21. EMBO Rep 12: 350-357, 2011.

50. Zhang XY, Varthi M, Sykes SM, Phillips C, Warzecha C, Zhu W, Wyce A, Thorne AW, Berger SL and McMahon SB: The putative cancer stem cell marker USP22 is a subunit of the human SAGA complex required for activated transcription and cell-cycle progression. Mol Cell 29: 102-111, 2008.

51. Zhang L, Lubin A, Chen H, Sun Z and Gong F: The deubiquitinating protein USP24 interacts with DDB2 and regulates DDB2 stability. Cell Cycle 11: 4378-4384, 2012.

52. Stouffs K, Lissens W, Tournaye H, Van Steirteghem A and Liebaers I: Possible role of USP26 in patients with severely impaired spermatogenesis. Eur J Hum Genet 13: 336-340, 2005.

53. Weber A, Heinlein M, Dengjel J, Alber C, Singh PK and Häcker G: The deubiquitinase Usp27x stabilizes the BH3-only protein Bim and enhances apoptosis. EMBO Rep 17: 724-738, 2016.

54. Popov N, Wanzel M, Madiredjo M, Zhang D, Beijersbergen R, Bernards R, Moll R, Elledge SJ and Eilers M: The ubiquitin-specific protease USP28 is required for MYC stability. Nat Cell Biol 9: 765-774, 2007.

55. Liu J, Chung HJ, Vogt M, Jin Y, Malide D, He L, Dundr M and Levens D: JTV1 co-activates FBP to induce USP29 transcription and stabilize p53 in response to oxidative stress. EMBO J 30: 846-858, 2011.

56. Zhao LJ, Zhang T, Feng XJ, Chang J, Suo FZ, Ma JL, Liu YJ, Liu Y, Zheng YC and Liu HM: USP28 contributes to the proliferation and metastasis of gastric cancer. J Cell Biochem: Nov 28, 2018 (Epub ahead of print). doi: 10.1002/jcb.28040.

57. Wang C, Yang C, Ji J, Jiang J, Shi M, Cai Q, Yu Y, Zhu Z and Zhang J: Deubiquitinating enzyme USP20 is a positive regulator of Claspin and suppresses the malignant characteristics of gastric cancer cells. Int J Oncol: Mar 8, 2017 (Epub ahead of print). doi: 10.3892/ijo.2017.3904.
58. Ma Y, Fu HL, Wang Z, Huang H, Ni J, Song J, Xia Y, Jin WL and Cui DX: USP22 maintains gastric cancer stem cell stemness and promotes gastric cancer progression by stabilizing BMI1 protein. Oncotarget 8: 33329-33342, 2017

59. He Y, Jin YJ, Zhang YH, Meng HX, Zhao BS, Jiang Y, Zhu JW, Liang GY, Kong D and Jin XM: Ubiquitin-specific peptidase 22 overexpression may promote cancer progression and poor prognosis in human gastric carcinoma. Transl Res 16: 407-416, 2015.

60. Yang DD, Cui BB, Sun LY, Zheng HQ, Huang Q, Tong JX and Zhang QF: The co-expression of USP22 and BMI-1 may promote cancer progression and predict therapy failure in gastric carcinoma. Cell Biochem Biophys 61: 703-710, 2011.

61. Nicassio F, Corrado N, Vissers JH, Areces LB, Bergink S, Marteijn JA, Geverts B, Houtsmuller AB, Vermeulen W, Di Fiore PP and Citterio E: Human USP3 is a chromatin modifier required for $\mathrm{S}$ phase progression and genome stability. Curr Biol 17: 1972-1977, 2007.

62. Bingol B, Tea JS, Phu L, Reichelt M, Bakalarski CE, Song Q Foreman O, Kirkpatrick DS and Sheng M: The mitochondrial deubiquitinase USP30 opposes parkin-mediated mitophagy. Nature 510: 370-375, 2014.

63. Tzimas C, Michailidou G, Arsenakis M, Kieff E, Mosialos G and Hatzivassiliou EG: Human ubiquitin specific protease 31 is a deubiquitinating enzyme implicated in activation of nuclear factor-kappaB. Cell Signal 18: 83-92, 2006.

64. Akhavantabasi S, Akman HB, Sapmaz A, Keller J, Petty EM and Erson AE: USP32 is an active, membrane-bound ubiquitin protease overexpressed in breast cancers. Mamm Genome 21: 388-397, 2010.

65. Sy SM, Jiang J, O WS, Deng Y and Huen MS: The ubiquitin specific protease USP34 promotes ubiquitin signaling at DNA double-strand breaks. Nucleic Acids Res 41: 8572-8580, 2013.

66. Wang Y, Serricchio M, Jauregui M, Shanbhag R, Stoltz T, Di Paolo CT, Kim PK and McQuibban GA: Deubiquitinating enzymes regulate PARK2-mediated mitophagy. Autophagy 11: 595-606, 2015.

67. Endo A, Matsumoto M, Inada T, Yamamoto A, Nakayama KI, Kitamura $\mathrm{N}$ and Komada M: Nucleolar structure and function are regulated by the deubiquitylating enzyme USP36. J Cell Sci 122: 678-686, 2009.

68. Huang X, Summers MK, Pham V, Lill JR, Liu J, Lee G, Kirkpatrick DS,Jackson PK,Fang G and Dixit VM: Deubiquitinase USP37 is activated by CDK2 to antagonize APC(CDH1) and promote $S$ phase entry. Mol Cell 42: 511-523, 2011.

69. Lin M, Zhao Z, Yang Z, Meng Q, Tan P, Xie W, Qin Y, Wang RF and Cui J: USP38 Inhibits type I interferon signaling by editing TBK1 Ubiquitination through NLRP4 Signalosome. Mol Cell 64: 267-281, 2016.

70. van Leuken RJ, Luna-Vargas MP, Sixma TK, Wolthuis RM and Medema RH: Usp39 is essential for mitotic spindle checkpoint integrity and controls mRNA-levels of aurora B. Cell Cycle 7: 2710-2719, 2008

71. Fang CL, Lin CC, Chen HK, Hseu YC, Hung ST, Sun DP, Uen YH and Lin KY: Ubiquitin-specific protease 3 overexpression promotes gastric carcinogenesis and is predictive of poor patient prognosis. Cancer Sci 109: 3438-3449, 2018.

72. Chen Y, Pang X, Ji L, Sun Y and Ji Y: Reduced expression of deubiquitinase USP33 is associated with tumor progression and poor prognosis of gastric adenocarcinoma. Med Sci Monit 24: 3496-505, 2018.

73. Wang X, Yu Q, Huang L and Yu P: Lentivirus-mediated inhibition of USP39 suppresses the growth of gastric cancer cells via PARP activation. Mol Med Rep 14: 301-306, 2016.

74. Dong X, Su H, Jiang F, Li H, Shi G and Fan L: miR-133a, directly targeted USP39, suppresses cell proliferation and predicts prognosis of gastric cancer. Oncol Lett 15: 8311-3818, 2018.

75. Zhang L,Zhou F,Drabsch Y, GaoR,Snaar-Jagalska BE,Mickanin C, Huang H, Sheppard KA, Porter JA, Lu CX and ten Dijke P: USP4 is regulated by AKT phosphorylation and directly deubiquitylates TGF- $\beta$ type I receptor. Nat Cell Biol 14: 717-726, 2012.

76. Li Y, Schrodi S, Rowland C, Tacey K, Catanese J and Grupe A Genetic evidence for ubiquitin-specific proteases USP24 and USP40 as candidate genes for late-onset Parkinson disease. Hum Mutat 27: 1017-1023, 2006

77. Pinilla-Vera M, Xiong Z, Zhao Y, Zhao J, Donahoe MP, Barge S, Horne WT, Kolls JK, McVerry BJ, Birukova A, et al: Full spectrum of LPS activation in alveolar macrophages of healthy volunteers by whole transcriptomic profiling. PLoS One 11: e0159329, 2016. 
78. Hock AK, Vigneron AM, Carter S, Ludwig RL and Vousden KH: Regulation of $\mathrm{p} 53$ stability and function by the deubiquitinating enzyme USP42. EMBO J 30: 4921-4930, 2011.

79. He L, Liu X, Yang J, Li W, Liu S, Liu X, Yang Z, Ren J, Wang Y, Shan L, et al: Imbalance of the reciprocally inhibitory loop between the ubiquitin-specific protease USP43 and EGFR/PI3K/AKT drives breast carcinogenesis. Cell Res 28: 934-951, 2018

80. Borrero J, Jimenez JJ, Gutiez L, Herranz C, Cintas LM and Hernandez PE: Use of the usp45 lactococcal secretion signal sequence to drive the secretion and functional expression of enterococcal bacteriocins in Lactococcus lactis. Appl Microbiol Biotechnol 89: 131-143, 2011.

81. Schweitzer K and Naumann M: CSN-associated USP48 confers stability to nuclear NF-kappaB/RelA by trimming K48-linked Ub-chains. Biochim Biophys Acta 1853: 453-469, 2015.

82. Weinstock J, Wu J, Cao P, Kingsbury WD, McDermott JL, Kodrasov MP, McKelvey DM, Suresh Kumar KG, Goldenberg SJ, Mattern MR and Nicholson B: Selective dual inhibitors of the cancer-related deubiquitylating proteases USP7 and USP47. ACS Med Chem Lett 3: 789-792, 2012.

83. Zhang B, Yin Y, Hu Y, Zhang J, Bian Z, Song M, Hua D and Huang Z: MicroRNA-204-5p inhibits gastric cancer cell proliferation by downregulating USP47 and RAB22A. Med Oncol 32: $331,2015$.

84. Naghavi L, Schwalbe M, Ghanem A and Naumann M: Deubiquitinylase USP47 promotes RelA phosphorylation and survival in gastric cancer cells. Biomedicines 6: pii: E62, 2018.

85. Hou K, Zhu Z, Wang Y, Zhang C, Yu S, Zhu Q and Yan B: Overexpression and biological function of ubiquitin-specific protease 42 in gastric cancer. PLoS One 11: e0152997, 2016.

86. Nishimura S, Oki E, Ando K, Iimori M, Nakaji Y, Nakashima Y, Saeki H, Oda Y and Maehara Y: High ubiquitin-specific protease 44 expression induces DNA aneuploidy and provides independent prognostic information in gastric cancer. Cancer Med 6: 1453-1464, 2017

87. Dayal S, Sparks A, Jacob J, Allende-Vega N, Lane DP and Saville MK: Suppression of the deubiquitinating enzyme USP5 causes the accumulation of unanchored polyubiquitin and the activation of p53. J Biol Chem 284: 5030-5041, 2009.

88. Aressy B, Jullien D, Cazales M, Marcellin M, Bugler B, Burlet-Schiltz O and Ducommun B: A screen for deubiquitinating enzymes involved in the $\mathrm{G}_{2} / \mathrm{M}$ checkpoint identifies USP50 as a regulator of HSP90-dependent Weel stability. Cell Cycle 9: 3815-3822, 2010.

89. Wang Z, Zhang H, Liu J, Cheruiyot A, Lee JH, Ordog T, Lou Z, You Z and Zhang Z: USP51 deubiquitylates H2AK13,15ub and regulates DNA damage response. Genes Dev 30: 946-959, 2016

90. Yang S, Liu L, Cao C, Song N, Wang Y, Ma S, Zhang Q, Yu N, Ding X, Yang F, et al: USP52 acts as a deubiquitinase and promotes histone chaperone ASF1A stabilization. Nat Commun 9: 1285,2018

91. Kazmierczak M, Harris SL, Kazmierczak P, Shah P, Starovoytov V, Ohlemiller KK and Schwander M: Progressive hearing loss in mice carrying a mutation in Usp53. J Neurosci 35 15582-15598, 2015.

92. Fraile JM, Campos-Iglesias D, Rodriguez F, Espanol Y and Freije JM: The deubiquitinase USP54 is overexpressed in colorectal cancer stem cells and promotes intestinal tumorigenesis. Oncotarget 7: 74427-74434, 2016.

93. Liu Y, Wang WM, Zou LY, Li L, Feng L, Pan MZ, Lv MY, Cao Y, Wang H, Kung HF, et al: Ubiquitin specific peptidase 5 mediates Histidine-rich protein Hpn induced cell apoptosis in hepatocellular carcinoma through P14-P53 signaling. Proteomics: 17, 2017 doi: 10.1002/pmic.201600350.

94. Oliveira AM, Perez-Atayde AR, Inwards CY, Medeiros F, Derr V, Hsi BL, Gebhardt MC, Rosenberg AE and Fletcher JA: USP6 and CDH11 oncogenes identify the neoplastic cell in primary aneurysmal bone cysts and are absent in so-called secondary aneurysmal bone cysts. Am J Pathol 165: 1773-1780, 2004.

95. Kang A, Kumar JB, Thomas A and Bourke AG: A spontaneously resolving breast lesion: Imaging and cytological findings of nodular fasciitis of the breast with FISH showing USP6 gene rearrangement. BMJ Case Rep 2015: pii: bcr2015213076, 2015.

96. Jian F, Cao Y, Bian L and Sun Q: USP8: A novel therapeutic target for Cushing's disease. Endocrine 50: 292-296, 2015.

97. Fu X, Xie W, Song X, Wu K, Xiao L, Liu Y and Zhang L: Aberrant expression of deubiquitylating enzyme USP9X predicts poor prognosis in gastric cancer. Clin Res Hepatol Gastroenterol 41: 687-692, 2017.
98. Deng S, Zhou H, Xiong R, Lu Y, Yan D, Xing T, Dong L, Tang E and Yang H: Over-expression of genes and proteins of ubiquitin specific peptidases (USPs) and proteasome subunits (PSs) in breast cancer tissue observed by the methods of RFDD-PCR and proteomics. Breast Cancer Res Treat 104: 21-30, 2007.

99. Xia JT, Chen LZ, Jian WH, Wang KB, Yang YZ, He WL, Chen D and Li W: MicroRNA-362 induces cell proliferation and apoptosis resistance in gastric cancer by activation of NF-B signaling. J Transl Med 12: 33, 2014.

100. Sun B, Li L, Ma W, Wang S and Huang C: MiR-130b inhibits proliferation and induces apoptosis of gastric cancer cells via CYLD. Tumour Biol 37: 7981-9787, 2016.

101. Bermejo JL, Kabisch M, Dunnebier T, Schnaidt S, Melchior F, Fischer HP, Harth V, Rabstein S, Pesch B, Brüning T, et al: Exploring the association between genetic variation in the SUMO isopeptidase gene USPL1 and breast cancer through integration of data from the population-based GENICA study and external genetic databases. Int J Cancer 133: 362-372, 2013.

102. Mevissen TE, Hospenthal MK, Geurink PP, Elliott PR, Akutsu M, Arnaudo N, Ekkebus R, Kulathu Y, Wauer T, El Oualid F, et al: OTU deubiquitinases reveal mechanisms of linkage specificity and enable ubiquitin chain restriction analysis. Cell 154: 169-184, 2013.

103. Wiener R, Zhang X, Wang T and Wolberger C: The mechanism of OTUB1-mediated inhibition of ubiquitination. Nature 483: 618-622, 2012

104. Kato K, Nakajima K, Ui A, Muto-Terao Y, Ogiwara H and Nakada S: Fine-tuning of DNA damage-dependent ubiquitination by OTUB2 supports the DNA repair pathway choice. Mol Cell 53: 617-630, 2014

105. Wang YQ, Zhang QY, Weng WW, Wu Y, Yang YS, Shen C, Chen XC, Wang L, Liu KJ, Xu MD and Sheng WQ: Upregulation of the Non-coding RNA OTUB1-isoform 2 contributes to gastric cancer cell proliferation and invasion and predicts poor gastric cancer prognosis. Int J Biol Sci 12: 545-557, 2016.

106. Carneiro AP, Reis CF, Morari EC, Maia YC, Nascimento R, Bonatto JM, de Souza MA, Goulart LR and Ward LS: A putative OTU domain-containing protein 1 deubiquitinating enzyme is differentially expressed in thyroid cancer and identifies less-aggressive tumours. Br J Cancer 111: 551-558, 2014.

107. Flierman D, van der Heden van Noort GJ, Ekkebus R, Geurink PP, Mevissen TE, Hospenthal MK, Komander D and Ovaa $\mathrm{H}$ : Non-hydrolyzable diubiquitin probes reveal linkage-specific reactivity of deubiquitylating enzymes mediated by S2 pockets. Cell Chem Biol 23: 472-482, 2016.

108. Yuan L, Lv Y, Li H, Gao H, Song S, Zhang Y, Xing G, Kong X, Wang L, Li Y, et al: Deubiquitylase OTUD3 regulates PTEN stability and suppresses tumorigenesis. Nat Cell Biol 17: 1169-1181, 2015.

109. Zhao Y, Majid MC, Soll JM, Brickner JR, Dango S and Mosammaparast N: Noncanonical regulation of alkylation damage resistance by the OTUD4 deubiquitinase. EMBO J 34: 1687-1703, 2015

110. Luo J, Lu Z, Lu X, Chen L, Cao J, Zhang S, Ling Y and Zhou X: OTUD5 regulates p53 stability by deubiquitinating p53. PLoS One 8: e77682, 2013.

111. Kim SY, Kwon SK, Lee SY and Baek KH: Ubiquitin-specific peptidase 5 and ovarian tumordeubiquitinase 6 A are differentially expressed in $\mathrm{p}^{+/+}$and p53 $3^{-/}$HCT116 cells. Int J Oncol: Mar 5, 2018 (Epub ahead of print). doi: 10.3892/ijo.2018.4302

112. Santiago-Sim T, Burrage LC, Ebstein F, Tokita MJ, Miller M, Bi W, Braxton AA, Rosenfeld JA, Shahrour M, Lehmann A, et al: Biallelic variants in OTUD6B cause an intellectual disability syndrome associated with seizures and dysmorphic features. Am J Hum Genet 100: 676-688, 2017.

113. Evans PC, Smith TS, Lai MJ, Williams MG, Burke DF, Heyninck K, Kreike MM, Beyaert R, Blundell TL and Kilshaw PJ: A novel type of deubiquitinating enzyme. J Biol Chem 278: 23180-23186, 2003.

114. Xu Z, Pei L, Wang L, Zhang F, Hu X and Gui Y: Snail1-dependent transcriptional repression of Cezanne2 in hepatocellular carcinoma. Oncogene 33: 2836-2845, 2014.

115. Virdee S, Ye Y, Nguyen DP, Komander D and Chin JW: Engineered diubiquitin synthesis reveals Lys29-isopeptide specificity of an OTU deubiquitinase. Nat Chem Biol 6: 750-757, 2010.

116. Guo T, Zhang Y, Qu X, Che X, Li C, Fan Y, Wan X, Ma R, Hou K, Zhou H, et al: miR-200a enhances TRAIL-induced apoptosis in gastric cancer cells by targeting A20. Cell Biol Int 42: 506-514, 2018

117. Lork M, Verhelst K and Beyaert R: CYLD, A20 and OTULIN deubiquitinases in NF-B signaling and cell death: So similar, yet so different. Cell Death Differ 24: 1172-1183, 2017. 
118. Weng W, Zhang Q, Xu M, Wu Y, Zhang M, Shen C, Chen X, Wang Y and Sheng W: OTUB1 promotes tumor invasion and predicts a poor prognosis in gastric adenocarcinoma. Am J Transl Res 8: 2234-2244, 2016.

119. Wang X, Zhang L, Zhang Y, Zhao P, Qian L, Yuan Y, Liu J, Cheng Q, Xu W, Zuo Y, et al: JOSD1 negatively regulates type-I interferon antiviral activity by deubiquitinating and stabilizing SOCS1. Viral Immunol 30: 342-349, 2017.

120. Zhang B, Zheng A, Hydbring P, Ambroise G, Ouchida AT, Goiny M, Vakifahmetoglu-Norberg H and Norberg E: PHGDH defines a metabolic subtype in lung adenocarcinomas with poor prognosis. Cell Rep 19: 2289-2303, 2017.

121. Zhang J, Huang JY, Chen YN, Yuan F, Zhang H, Yan FH, Wang MJ, Wang G, Su M, Lu G, et al: Whole genome and transcriptome sequencing of matched primary and peritoneal metastatic gastric carcinoma. Sci Rep 5: 13750, 2015.

122. Butler LR, Densham RM, Jia J, Garvin AJ, Stone HR, Shah V, Weekes D, Festy F, Beesley J and Morris JR: The proteasomal de-ubiquitinating enzyme $\mathrm{POH} 1$ promotes the double-strand DNA break response. EMBO J 31: 3918-3934, 2012.

123. Py BF, Kim MS, Vakifahmetoglu-Norberg H and Yuan J: Deubiquitination of NLRP3 by BRCC3 critically regulates inflammasome activity. Mol Cell 49: 331-338, 2013.

124. Sun H, Guo D, Su Y, Yu D, Wang Q, Wang T, Zhou Q, Ran X and Zou Z: Hyperplasia of pericytes is one of the main characteristics of microvascular architecture in malignant glioma. PLoS One 9: e114246, 2014.

125. Zhou L, Shi L, Guo H and Yao X: MYSM-1 suppresses migration and invasion in renal carcinoma through inhibiting epithelial-mesenchymal transition. Tumour Biol: Sep 27, 2015 (Epub ahead of print).

126. Xiao D, Yang S, Huang L, He H, Pan H and He J: COP9 signalosome subunit CSN5, but not CSN6, is upregulated in lung adenocarcinoma and predicts poor prognosis. J Thorac Dis 10: 1596-1606, 2018

127. Niu Z, Lei R, Shi J, Wang D, Shou W, Wang Z, Wang Y, Wang Z and Huang W: A polymorphism rs17336700 in the PSMD7 gene is associated with ankylosing spondylitis in Chinese subjects. Ann Rheum Dis 70: 706-907, 2011.

128. McCullough J, Clague MJ and Urbe S: AMSH is an endosome-associated ubiquitin isopeptidase. J Cell Biol 166 : 487-492, 2004.

129. Zhu W, Liu Y and Ling B: Quantum mechanics and molecular mechanics study of the cataly tic mechanism of human AMSH-LP domain deubiquitinating enzymes. Biochemistry 54: 5225-5234, 2015.

130. Wickramasinghe VO, Gonzalez-Porta M, Perera D, Bartolozzi AR, Sibley CR, Hallegger M, Ule J, Marioni JC and Venkitaraman AR: Regulation of constitutive and alternative mRNA splicing across the human transcriptome by PRPF8 is determined by 5' splice site strength. Genome Biol 16: 201, 2015.
131. Sang MM, Du WQ, Zhang RY, Zheng JN and Pei DS: Suppression of CSN5 promotes the apoptosis of gastric cancer cells through regulating p53-related apoptotic pathways. Bioorg Med Chem Lett 25: 2897-2901, 2015.

132. Wang X, Wang H, Zhao S, Sun P, Wen D, Liu T, Liu H, Yang Z and Ma Z: Eukaryotic translation initiation factor EIF3H potentiates gastric carcinoma cell proliferation. Tissue Cell 53: 23-29, 2018.

133. Cheng Y, Jia C, Li G and Li H: Expression of eukaryotic initiation factor $3 \mathrm{f}$ is associated with prognosis in gastric carcinomas. Oncol Res Treat 37: 198-202, 2014

134. Tahara H, Kay MA, Yasui W and Tahara E: MicroRNAs in cancer: The 22nd hiroshima cancer Seminar/the 4th Japanese Association for RNA interference joint international symposium, 30 August 2012, grand prince hotel Hiroshima. Jpn J Clin Oncol 43: 579-582, 2013

135. Huang S, Liu S, Fu JJ, Tony Wang T, Yao X, Kumar A, Liu G and $\mathrm{Fu} \mathrm{M}$ : Monocyte chemotactic protein-induced protein 1 and 4 form a complex but act independently in regulation of interleukin-6 mRNA degradation. J Biol Chem 290: 20782-20792, 2015.

136. Roy A and Kolattukudy PE: Monocyte chemotactic protein-induced protein (MCPIP) promotes inflammatory angiogenesis via sequential induction of oxidative stress, endoplasmic reticulum stress and autophagy. Cell Signal 24: 2123-2131, 2012

137. Mansour MA: Ubiquitination: Friend and foe in cancer. Int $J$ Biochem Cell Biol 101: 80-93, 2018.

138. Suk FM, Chang CC, Lin RJ, Lin SY, Chen YT and Liang YC: MCPIP3 as a potential metastasis suppressor gene in human colorectal cancer. Int J Mol Sci 19: E1350, 2018.

139. Bray F, Ferlay J, Soerjomataram I, Siegel RL, Torre LA and Jemal A: Global cancer statistics 2018: GLOBOCAN estimates of incidence and mortality worldwide for 36 cancers in 185 countries. CA Cancer J Clin 68: 394-424, 2018. 